\title{
Characterization of a new genotype of Betapapillomavirus HPV 17 through L1, E7, E7 and LCR sequences
}

\author{
L. OLIVEIRA, L. SANTOS, F. NEVES
}

Department of Microbiology and Parasitology, Fluminense Federal University, Rua Prof. Ernani Melo, 101 Niterói, RJ 24210-130, Brazil, 24210-130

Received August 21, 2017; revised November 20, 2017; accepted April 16, 2018

\begin{abstract}
Summary. - Human papillomavirus (HPV) exhibits epithelial and mucosal tropism. HPV type 17 belongs to the Betapapillomavirus genus and molecular cloning experiments have identified two subtypes (17a and 17b) isolated from epidermodysplasia verruciformis (EV). HPV subtypes are characterized by dissimilarities from 2 to $10 \%$ at the nucleotide level from their referenced HPV. The aim of this study was to characterize the L1, E6, E7 and LCR sequences from an isolate, which was recovered from the oral mucosa of an asymptomatic 63 year-old woman. The whole late gene 1 (L1) was amplified using several sets of primers. The complete early genes 6 and 7 (E6, E7) and the long control region (LCR) were amplified using specific primers. Potential binding sites for transcriptional factors within the LCR were also investigated. Within these sets, the DNA sequence was altered at 91 positions (68 in L1, 13 in E6, 8 in E7, and 2 in LCR sequences). L1 analysis showed high dissimilarity compared with the HPV 17 prototype, reaching $4 \%$ of nucleotide substitutions and leading to a probable third 17 subtype. The E6 oncoprotein presented the highest modification among the sequences studied, with four amino acid changes in comparison with the prototype isolate. One amino acid was modified at a position 62 (S-T), a zinc-binding domain $(\mathrm{CxxC}(\mathrm{C}) 29 \mathrm{CxxC})$. Our findings provide data on genetic variations seen in this genotype, reaching to dichotomic branching and pointing to an evolutionary process.
\end{abstract}

Keywords: betapapillomavirus; HPV 17; subtype; oral cavity

\section{Introduction}

To date, 170 human papillomavirus (HPV) types have been wholly characterized, and approximately 60 of them exhibit epithelial and mucosal tropism (De Villiers et al., 2013). They are among the most common sexually transmitted viral agents and are normally associated with both benign and malignant genital diseases. The virus can be observed in several body regions, such as the skin and the genital and oral mucosa, being quite well adapted to these ecological niches. Papillomavirus genotypes have been classified according to the entire L1 gene, a highly conserved open reading frame (ORF), which has 1,524 bp length in HPV 17 . Similarity at least $90 \%$ char-

*Corresponding author. E-mail: virologia.uff@gmail.com; phone: $+55-2126292430$.

Abbreviations: $\mathrm{EV}=$ epidermodysplasia verruciformis; $\mathrm{HPV}=\mathrm{hu}-$ man papillomavirus; SCC $=$ squamous carcinoma acterizes the viral type and dissimilarity from $2-10 \%$ classifies a subtype. HPV 17 belongs to cluster $b 2$ of Betapapillomavirus (De Villiers et al., 2013). This cluster is characterized by a short genome length $(7,427 \mathrm{bp})$. Molecular cloning experiments have identified two subtypes (17a and 17b) isolated from patients with epidermodysplasia verruciformis (EV). HPV 17 normally infects the skin epithelium and was first isolated from benign maculas and subsequently from a squamous carcinoma (SCC) and malignant melanoma in one immunocompromised patient. It has also been found in keratoacantoma (benign skin tumor) and actinic keratosis (considered as precursor lesion for SCC) (Ekström et al., 2011). The HPV types associated with EV are rare in typical skin lesions. A partial key to the host restriction of these viruses may be due to the unusual organization of their LCR region, which is shorter than other HPV genotypes (May et al., 1991).

Since HPV type 17 exhibits tropism to skin cells, its detection in oral mucosa is very unusual, although the 
amplification of viral DNA with new primers has increased the spectrum of HPV 17 isolates in the oral cavity (Bottalico et al., 2011). However, few of these genotypes have been sequenced to date, as can be seen in GenBank accessions. HPV 17 has been associated with the development of skin cancer in EV patients (Nindl et al., 2007) and with non-genital seborrheic keratosis (Li et al., 2004). However, the cutaneous HPV types are not classified as cancer risks. Betapapillomavirus species were previously considered almost exclusively skin types. They have been found in healthy people and individuals with skin tumors, including immunosuppressed and immunocompetent ones (Antonsson et al., 2000; Pfister et al., 2003). Regardless of being found in asymptomatic people or associated with benign and malignant skin lesions, their study has implication for understanding the oral colonization by HPV types previously discovered in other body sites. New variants isolated from oral mucosa could also differ in biological properties. We began this study by searching concordant viral genotypes in the oral and genital regions from 84 randomly selected asymptomatic women. After genotyping the positive HPV samples from both sites, we found HPV type 17 in the oral mucosa from one individual. In order to identify this one, we sequenced the whole viral genes L1, E6, E7 and the LCR region located between $\mathrm{L} 1$ and E6 genes.

\section{Material and Methods}

DNA extraction. HPV 17 DNA was extracted from an oral smear of a woman previously analyzed for HPV cervical infection, for which the result was negative. This woman was 63 years old, negative for HIV infection, a widow, with no schooling, of low income class, and a smoker of over 20 cigarettes a day. The Ethics Committee of the College of Medicine at the University approved the protocols for collection and informed consent (CAAE 0037.0.258.000-10). DNA was extracted from the oral and cervical samples using a commercial assay kit (Invisorb, Unisciencel, São Paulo, Brazil).
PCR reactions and sequencing. HPV detection was done by polymerase chain reaction (PCR). MY09/11 consensus primers were used to amplify a $450 \mathrm{bp} \mathrm{L1}$ sequence, comprising one third of the major capsid protein. The primers were aligned to reveal the sequence from 6,761 to $7,090 \mathrm{bp}$, within the complete sequence $5,724-7,247$ bp. Each cycle included a denaturation step at $94^{\circ} \mathrm{C}$ for $1 \mathrm{~min}$, an annealing step at $55^{\circ} \mathrm{C}$ for $2 \mathrm{~min}$ and an elongation step at $72^{\circ} \mathrm{C}$ for 2 min using a DNA Thermal Cycler (Applied Biosystems, California, USA). The amplified PCR product was purified using a Illustra GFX PCR DNA and Gel Band Purification Kit (GE HealthCare, São Paulo, Brazil) and directly sequenced using a Big Dye Terminator v3.1 Cycle sequencing kit in an ABI DNA sequencer 3130 (Applied Biosystems, California, USA) with the same primers used for PCR amplification. The forward and reverse sequences were aligned and analyzed using Clustal $\mathrm{W}$ in the BioEdit Sequence Alignment Editor (North Carolina State University, Raleigh, NC) (Thompson et al., 1994). The similarity analysis was performed by BLAST (Alignment Search Tool Analysis) (Altschul et al., 1997).

After genotype identification, different sets of primers were used to investigate the HPV 17 genes, according to the reference sequence for HPV type 17 isolate (GenBank accession number X74469) (Delius and Hofman, 1994). To amplify the whole L1 sequence, the primers designed are listed in the Table 1 . The annealing temperature of all primers was $58^{\circ} \mathrm{C}$. These primers were used to sequence partials fragments of the whole sequence. To amplify E6, E7 and LCR sequences, specific primers were designed: (i) for E6 gene (product length 567 bp): FWE6 (nt138-158) 5'GTG ACC GCC TTC GTT ACC TTA 3' and RVE6 (nt685-704) 5' TCG TAG CAA TGC AGG TCA GT 3'; (ii) for E7 gene (product length $497 \mathrm{bp}$ ): FWE7 (nt593-612) 5'GGC TTG TGC AGA CAT TGT GG 3'; RVE7 (nt1070-1089) 5'TCG CGG GAG TTT CCC TGT AT 3', and (iii) for LCR gene (product length $426 \mathrm{bp}$ ): Primers were used to cover the whole sequence (622-909 bp), flanking 604 to 1,040 bp; FWLCR (nt7250-7272) 5'GCTTTCGGTCTCTCA ATA AACAA 3' and RVLCR (nt229-248) 5'ACA AGG TAT CAG CAA GCT CC 3'.

The PCR amplification for the whole E6 and E7 genes was performed using $50 \mathrm{pmol}$ of different sets of primers. Amplifica-

Table 1. Primers designed for the whole L1 HPV 17 sequence

\begin{tabular}{cclcc}
\hline Gene & Primer name & Sequence 5' to 3' & Primers positions & Product size(bp) \\
\hline 17L1 & BFL1 & GCAGAAGCAGGAGGCCAGATT & $5640-5659$ & 451 \\
& BRL1 & AGGGATGTCCTGTAGTGCCT & $6090-6071$ & 464 \\
CFL1 & GCAGGCCTTGAGATAGGACG & $6033-6052$ & 586 \\
CRL1 & GCATAGACTGCTCTCGTCT & $6496-6477$ & 452 \\
DFL1 & GGACAGGGCTCCTGTATGTG & $6230-6249$ & $6814-6795$ \\
& DRL1 & TGTAACAGCCCCAGCTTCTG & $6960-6980$ & $7411-7392$ \\
& EFL1 & TGGCAGTTAGGATTTGTGCCT & & \\
& ERL1 & CGGTGCTTCCACAAAAGCA & &
\end{tabular}


tion was conducted in $50 \mu \mathrm{l}$ of reaction mixture (1x PCR buffer, $200 \mathrm{mmol} / \mathrm{l} \mathrm{dNTPs}, 1.5 \mathrm{mmol} / \mathrm{l} \mathrm{MgCl}_{2}, 50 \mathrm{pmol}$ of each primer, 0.25 U Taq polymerase (Invitrogen Brazil, São Paulo, SP, Brazil) and $5 \mu$ of the extracted DNA sample with 30 amplification cycles. Each cycle included a denaturation step at $94^{\circ} \mathrm{C}$ for $30 \mathrm{~s}$, an annealing step at $60^{\circ} \mathrm{C}$ for $1 \mathrm{~min}$ and a chain elongation step at $72^{\circ} \mathrm{C}$ for $1 \mathrm{~min}$, on DNA Thermal Cycler (Verity, Applied Biosystems, California, USA). The LCR sequence was amplified at a $57^{\circ} \mathrm{C}$ annealing temperature using the same protocol. The amplified PCR product of each selected gene was sequenced in both strands with the same primers used for PCR amplification.

In silico analyses. The results were analyzed using the BioEdit Sequence Alignment Editor (North Carolina State University, Raleigh, NC) and aligned using uMuscle (Edgar, 2004). Nucleotides that differed from the prototype were recorded as genomic variations. Nucleotide distances were determined by p-distance. The GenBank database (Benson et al., 2008) was queried to retrieve all available sequences for HPV 17. Phylogenetic trees were created using the neighbor-joining method, and bootstrap analyses (1,000 replicates) were performed to test the tree confidence for the sequences (Mega package, v 6.0) (Tamura et al., 2013). Phylogenies on aligned amino acid sequences were constructed using the same program.

The $\mathrm{MATCH}^{\mathrm{TM}}$ Gene regulation software (Kel et al., 2003) and the TRANSFAC database (Matys et al., 2006) were used to search for transcriptional factors within the LCR sequence that had been previously described to bind this HPV 17 region: E2, API and the TATA box (Ensser and Pfister, 1990). Cut-off values and coincidence levels between consensus binding sites and LCR sequence of each type were adjusted in order to minimize both the number of negative and positive faults.

\section{Results and Discussion}

Using the traditional My09/My11 primers pair, a new HPV 17 variant far from the prototype was detected. Hazard et al. (2007) validated the FA fragment (about 480 nucleotides) as a robust tool to classify HPV types and subtypes, comparing L1 ORF, My and FA fragments. According to their results, My fragments are appropriated to taxonomic purposes. Very few subtypes have been described within the family Papillomaviridae in the past (De Villiers et al, 2004), but at the present, the more primer designs are appearing, more subtypes are being detected (Hazard et al., 2007), including those belonging to the Betapapillomavirus genus, uncommonly reported.

The L1, E6, E7 genes and the LCR sequence from an oral sample infected with the HPV 17 type were analyzed for possible nucleotide alterations and compared to the HPV 17 prototype. Within these regions, the DNA sequence

Table 2. Specific nucleotide changes within KY34886 isolate at nucleotide positions from 5724 to 7247 (L1)

\begin{tabular}{|c|c|c|c|c|c|c|c|c|c|c|c|c|c|c|c|c|c|c|c|c|c|c|c|c|c|c|c|c|c|c|c|c|c|c|}
\hline Nucleotide & 5 & 5 & 5 & 5 & 5 & 5 & 5 & 5 & 6 & 6 & 6 & 6 & 6 & 6 & 6 & 6 & 6 & 6 & 6 & 6 & 6 & 6 & 6 & 6 & 6 & 6 & 6 & 6 & 6 & 6 & 6 & 6 & 6 & 6 \\
\hline \multirow[t]{3}{*}{ position } & 8 & 8 & 8 & 8 & 9 & 9 & 9 & 9 & 0 & 0 & 0 & 0 & 0 & 0 & 1 & 1 & 1 & 1 & 2 & 2 & 3 & 3 & 3 & 4 & 4 & 5 & 5 & 5 & 5 & 6 & 6 & 6 & 6 & 7 \\
\hline & 4 & 5 & 8 & 9 & 0 & 3 & 5 & 6 & 0 & 1 & 5 & 7 & 8 & 9 & 2 & 2 & 5 & 6 & 3 & 9 & 0 & 0 & 1 & 7 & 9 & 1 & 3 & 4 & 6 & 0 & 0 & 1 & 1 & 1 \\
\hline & 3 & 8 & 8 & 7 & 3 & 9 & 1 & 3 & 5 & 4 & 6 & 4 & 9 & 2 & 5 & 8 & 2 & 4 & 5 & 0 & 2 & 5 & 7 & 3 & 7 & 8 & 0 & 7 & 6 & 5 & 8 & 1 & 4 & 9 \\
\hline KY348861 & $\mathrm{C}$ & $\mathrm{A}$ & $\mathrm{A}$ & $\mathrm{T}$ & G & G & $\mathrm{T}$ & $\mathrm{C}$ & A & G & G & $\mathrm{T}$ & $\mathrm{T}$ & $\mathrm{A}$ & $\mathrm{C}$ & $\mathrm{T}$ & $\mathrm{C}$ & $\mathrm{T}$ & A & A & $\mathrm{T}$ & A & $\mathrm{C}$ & $\mathrm{T}$ & $\mathrm{C}$ & $\mathrm{C}$ & $\mathrm{C}$ & $\mathrm{A}$ & $\mathrm{T}$ & $\mathrm{T}$ & A & $\mathrm{A}$ & $\mathrm{A}$ & $\mathrm{A}$ \\
\hline \multirow[t]{2}{*}{ X74469 } & $\mathrm{T}$ & $\mathrm{T}$ & $\mathrm{T}$ & $\mathrm{A}$ & A & A & $\mathrm{C}$ & $\mathrm{T}$ & $\mathrm{T}$ & A & $\mathrm{A}$ & $\mathrm{C}$ & $\mathrm{C}$ & G & $\mathrm{T}$ & $\mathrm{C}$ & $\mathrm{T}$ & G & G & G & $\mathrm{C}$ & $\mathrm{T}$ & $\mathrm{T}$ & $\mathrm{C}$ & $\mathrm{T}$ & A & $\mathrm{T}$ & G & $\mathrm{C}$ & $\mathrm{C}$ & $\mathrm{T}$ & G & $\mathrm{T}$ & $\mathrm{T}$ \\
\hline & & & & & & & & & & & & & & & & & & & 1 & & & & & & & & & 2 & & & & & & \\
\hline AA & & & & & & & & & & & & & & & & & & & 7 & & & & & & & & & 7 & & & & & & \\
\hline position & & & & & & & & & & & & & & & & & & & 1 & & & & & & & & & 2 & & & & & & \\
\hline KY348861 & & & & & & & & & & & & & & & & & & & K & & & & & & & & & $\mathrm{D}$ & & & & & & \\
\hline X74469 & & & & & & & & & & & & & & & & & & & $\mathrm{R}$ & & & & & & & & & $\mathrm{G}$ & & & & & & \\
\hline Nucleotide & 6 & 6 & 6 & 6 & 6 & 6 & 6 & 6 & 6 & 6 & 6 & 6 & 6 & 6 & 6 & 6 & 7 & 7 & 7 & 7 & 7 & 7 & 7 & 7 & 7 & 7 & 7 & 7 & 7 & 7 & 7 & 7 & 7 & 7 \\
\hline \multirow[t]{3}{*}{ position } & 7 & 7 & 7 & 7 & 7 & 7 & 7 & 8 & 8 & 8 & 8 & 8 & 9 & 9 & 9 & 9 & 0 & 0 & 0 & 0 & 0 & 1 & 1 & 1 & 1 & 1 & 1 & 1 & 1 & 2 & 2 & 2 & 2 & 2 \\
\hline & 3 & 3 & 4 & 4 & 5 & 8 & 9 & 0 & 3 & 5 & 6 & 7 & 5 & 7 & 7 & 9 & 0 & 6 & 7 & 8 & 9 & 1 & 2 & 4 & 5 & 5 & 7 & 9 & 9 & 1 & 1 & 2 & 2 & 2 \\
\hline & 1 & 7 & 6 & 9 & 2 & 8 & 4 & 0 & 9 & 7 & 3 & 5 & 9 & 1 & 7 & 3 & 7 & 1 & 6 & 5 & 1 & 9 & 7 & 5 & 2 & 4 & 8 & 5 & 6 & 7 & 8 & 0 & 8 & 9 \\
\hline KY348861 & $\mathrm{A}$ & $\mathrm{A}$ & $\mathrm{C}$ & $\mathrm{C}$ & G & $\mathrm{T}$ & $\mathrm{C}$ & $\mathrm{C}$ & G & G & A & $\mathrm{C}$ & $\mathrm{T}$ & $\mathrm{C}$ & A & $\mathrm{T}$ & $\mathrm{T}$ & $\mathrm{C}$ & $\mathrm{C}$ & A & $\mathrm{T}$ & $\mathrm{C}$ & G & $\mathrm{T}$ & $\mathrm{A}$ & G & $\mathrm{A}$ & G & $\mathrm{C}$ & $\mathrm{T}$ & $\mathrm{T}$ & $\mathrm{T}$ & $\mathrm{C}$ & $\mathrm{C}$ \\
\hline \multirow[t]{2}{*}{ X74469 } & G & G & G & $\mathrm{T}$ & A & $\mathrm{C}$ & $\mathrm{T}$ & A & A & A & G & $\mathrm{T}$ & $\mathrm{C}$ & $\mathrm{A}$ & G & $\mathrm{C}$ & $\mathrm{A}$ & A & $\mathrm{T}$ & G & A & $\mathrm{T}$ & $\mathrm{A}$ & $\mathrm{C}$ & $\mathrm{C}$ & A & G & $\mathrm{C}$ & $\mathrm{T}$ & G & $\mathrm{C}$ & $\mathrm{C}$ & $\mathrm{T}$ & $\mathrm{T}$ \\
\hline & & & & & & & 3 & & & & & & & & & 4 & & 4 & & & & & & & & & & 4 & 4 & 4 & & & & 5 \\
\hline AA & & & & & & & 5 & & & & & & & & & 2 & & 4 & & & & & & & & & & 9 & 9 & 9 & & & & 0 \\
\hline position & & & & & & & 9 & & & & & & & & & 4 & & 6 & & & & & & & & & & 1 & 1 & 9 & & & & 2 \\
\hline KY348861 & & & & & & & $\mathrm{D}$ & & & & & & & & & $\mathrm{S}$ & & $\mathrm{N}$ & & & & & & & & & & $\mathrm{S}$ & $\mathrm{T}$ & $\mathrm{S}$ & & & & I \\
\hline X74469 & & & & & & & $\mathrm{E}$ & & & & & & & & & $\mathrm{P}$ & & $\mathrm{K}$ & & & & & & & & & & $\mathrm{S}$ & $\mathrm{T}$ & $\mathrm{P}$ & & & & $\mathrm{T}$ \\
\hline
\end{tabular}

Each column and the numbers in first four rows represents a specific nucleotide position in the L1 sequence. The fifth row shows the nucleotides changes for the HPV 17 prototype, Acc. No. X74469 in the NCBI BLAST (sixth row). The seventh row shows the position of non-conservative amino acid changes. 
Table 3. Specific nucleotide changes within KP701189 (E6), KP70190 (E7) and KP701191 (LCR) isolates

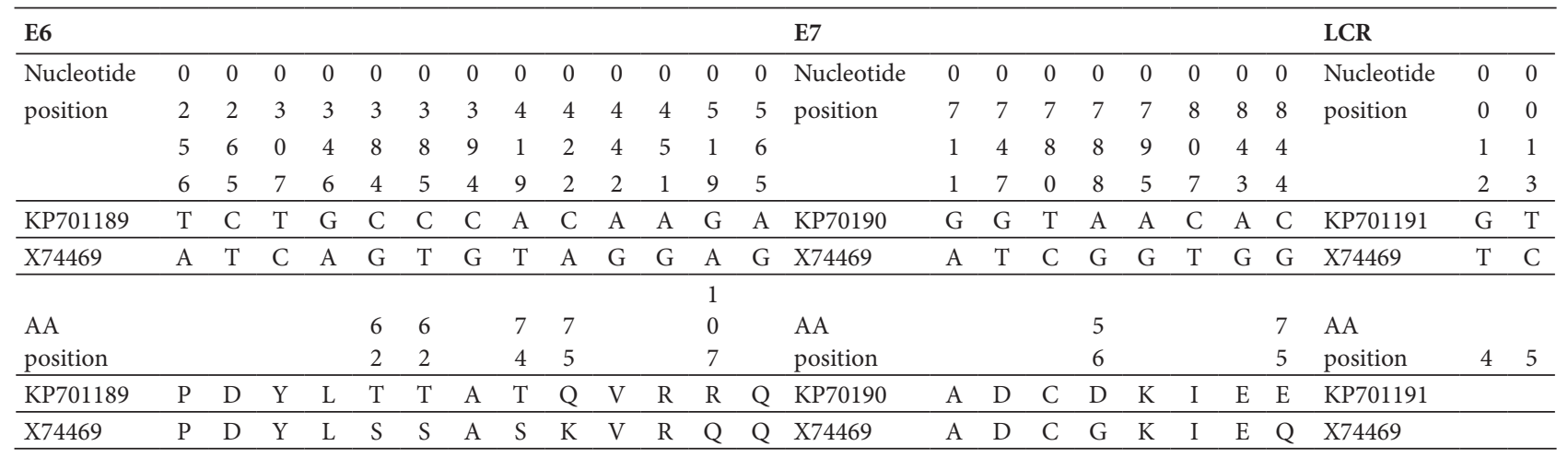

Specific nucleotide changes within E6 gene (200 to 625 bp), E7 (622 to 909 bp) and LCR (1 to 329 bp). Each column and the numbers in first four rows represents a specific nucleotide position in the sequence. The fifth row shows the nucleotides changes for the HPV 17 prototype, Acc. No. X74469 in the NCBI BLAST (sixth row). The seventh row shows the position of non-conservative amino acid changes.

was changed at 91 positions (68 in L1, 13 in E6, eight in E7, and two in LCR non coding region) (Tables 2 and 3). These sequences were submitted to GenBank and recorded under the accession numbers KY348861 (88L1WRJ), KP701189 (88E6RJ), KP70190 (88E7RJ) and KP701191 (88LCRRJ). No deletions or insertions were observed. The

(a)

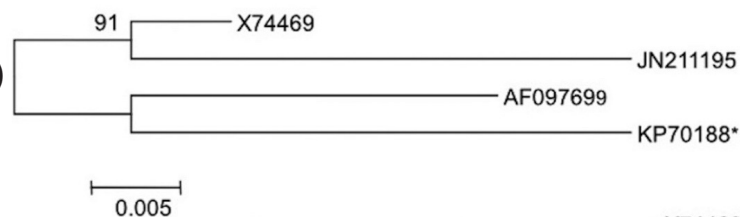

(b)

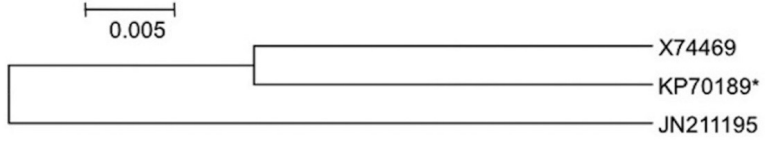

(c)

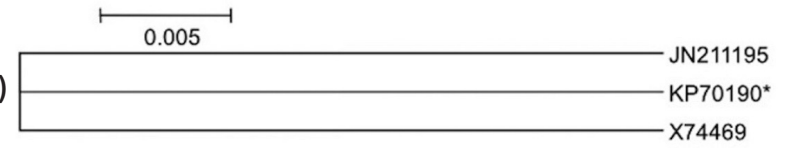

(d)

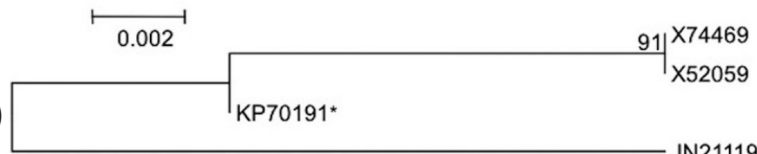

Fig. 1

Phylogenetic trees of L1 (a), E6 (b), E7 (c) and LCR (d) genetic sequences of HPV 17 (isolate compared with HPV 17 sequences available in the GenBank database)

Values of 1,000 bootstraps above $60 \%$ replicates are given at the branch of the L1 and LCR sequences. X74469, Prototype (Delius and Hofman, 1994); JN 21195, Isolate S 410, unpublished; Isolate 17b, L1 partial sequence (Berkout et al., 2000), X52059.1, LCR (Enser and Pfistter, 1990). Asterisks indicate the isolates detected in this study. isolate 88L1WRJ shared $94.0 \%$ (1456/1524 bp) identity in the whole L1 sequence with HPV type 17 . The complete E6, E7 and LCR gene sequences were analyzed, displaying 96.9\% (413/426), 97.2\% (280/288) and 99.4\% (327/329) identity with the prototype sequence, respectively. These findings revealed a genome not very close to it. Although two subtypes ("a" and "b") have been described for HPV 17 , the alignment of these regions with known sequences showed dissimilarity higher than $2 \%$. Isolates differing between $2-10 \%$ identity in the L1 sequence are considered to be subtypes, but the final result is defined by the whole genome sequencing (De Villiers et al., 2004). However, Ekstrom et al. (2011) not only classified but described new HPV types using small L1 DNA sequences. They also affirmed that shorter sequences within L1 ORF amplified with FA or My primers offer substantial results to identify new HPV types.

The L1 DNA sequence analysis showed a high number of nucleotide variations, reaching over $2 \%$ of the partial region. Eight of them resulted in non-conservative amino acid changes, at positions 6235 (R-K), 6547 (G-D), 6794 (E-D), 6993 (P-S), 7061 (K-N), 7195/7196 (T-S), 7217 (P-S) and 7229 (T-I). The remaining variations led to silent substitutions (Table 2).

The E6 oncoprotein presented the highest degree of variation among the sequences studied, with four amino acid changes in comparison with the prototype. The amino acid sequence was modified at positions 62 (S-T), 74 (S-T), 75 (K-Q) and 107 (Q-R) (Table 3). The alteration at position $62(\mathrm{~S}-\mathrm{T})$ is supposed to affect a zinc-binding domain (CxxC(C)29 CxxC).

The complete E7 nucleotide sequence showed two nonconservative alterations at positions $56(\mathrm{G}-\mathrm{D})$ and $75(\mathrm{Q}-\mathrm{E})$. Although not used as a classification criterion, the E6 and E7 oncogenic proteins revealed a significant distance from the 
prototype (Table 3). As the function of this motif is undefined, the meaning of the substitution is also unknown. On the other hand, alterations in the E7 protein did not lead to mutations in the zinc-binding domains or the $\mathrm{pRb}$ binding core sequence ( $\mathrm{LxCxE})$.

The LCR region, considered the most variable sequence of the HPV genome, displayed only two point mutations, which did not promote any modifications in potential binding sites (Table 3 ). TRANSFAC database revealed 10 putative binding sites in this region: one AP-1, two TATA and TATAA signals, five early proteins $\mathrm{E} 2$, two transcription factors (one myeloblastosis viral oncogene, $\mathrm{v}-\mathrm{MyB}$, and one nuclear transcription factor, Y-NFY). In general, LCR has less conserved genome segments. This regulatory segment has low restriction of mutations.

Concerning the phylogenetic tree presented in the Fig. 1, we could note the further L1 genetic distance among 88L1WRJ variant and the prototype (subtype A) or AF097699 isolate (subtype B). The concatenated E6, E7, LCR and $\mathrm{L} 1$ sequences generated a phylogenetic tree that showed a well delimited split between the isolate of this study and the others available in the GenBank (Fig. 2). This dichotomical division was quite evident when the most common

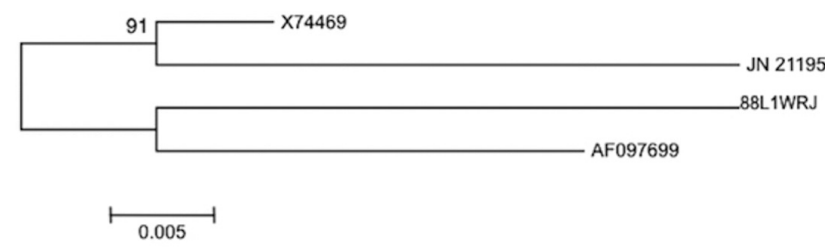

Fig. 2

Phylogenetic tree derived from a concatenated 88WRJ sequence aligment of L1, E6, E7 and LCR compared with HPV 17 sequences deposited in the GenBank database

X74469.1 (Delius and Hofman, 1994), JN 21195.1 (Isolate S 410, unpublished), AF097699.1 (Isolate 17b, L1 partial sequence, Berkout et al., 2000), X52059.1, LCR (Enser and Pfistter, 1990).

EV-associated HPV were clustered together in a partial L1 gene-based phylogenetic tree.

Phylogenetic comparisons were also performed by concatenating the sequences of the four genes analyzed in the present study. Due to the small number of sequences of HPV 17 type available in the GenBank database, the analysis of phylogenetic trees was somewhat impaired. The isolate was identified as a variant highly dissimilar from the other

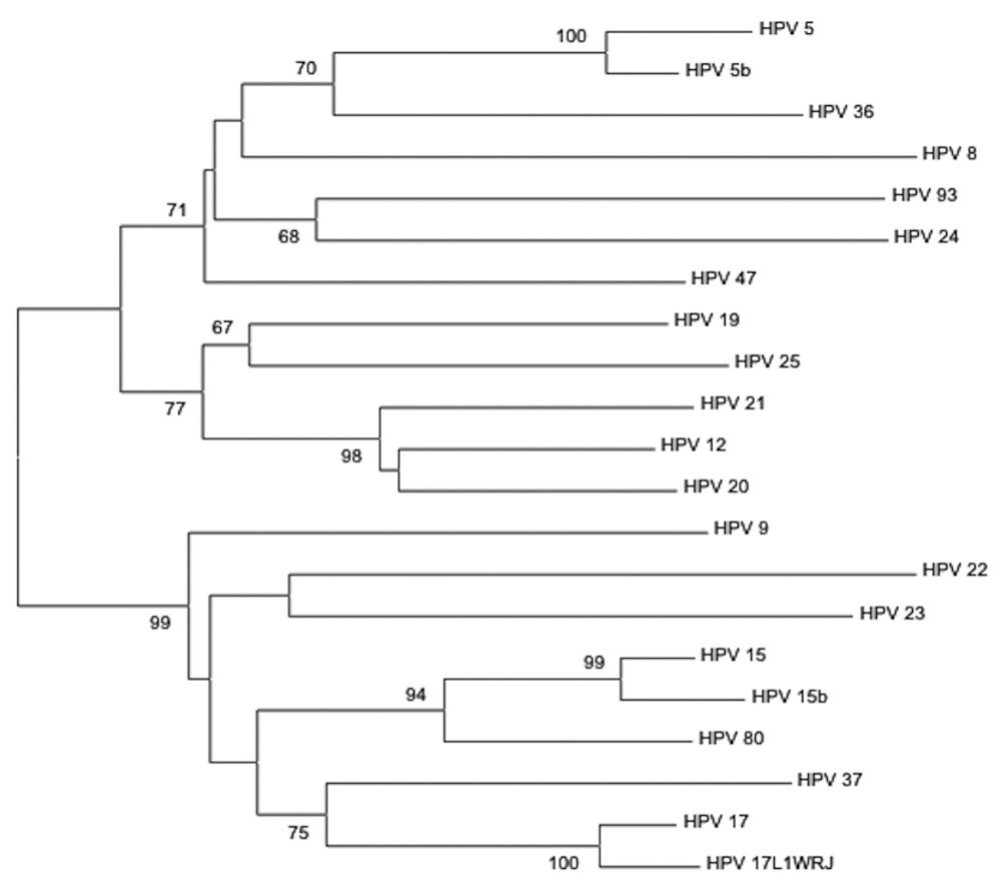

Fig. 3

Phylogenetic neighbor-joining tree constructed using L1 HPV 17 isolate (KY34886) and other sequences available in GenBank M17463, HPV 5 (Zachow et al., 1987); D90252, HPV 5b (Yabe et al., 1991); X74471, HPV 8 (Fuchs et al.,1986); X74464, HPV 9 (Delius and Hofmann, 1994); X74466, HPV 12 (Delius and Hofmann, 1994); X74468, HPV 15 (Delius and Hofmann, 1994); AF091437, HPV 15b (Berkout et al. 2000); X74469, HPV 17 (Delius and Hofmann, 1994); X74470, HPV 19 (Delius and Hofmann, 1994); U31778, HPV 20 (Kremsdorf et al., 1984); U31779, HPV 21 (Kremsdorf et al., 1984); U31780, HPV 22 (Kremsdorf et al., 1984); U31781, HPV 23 (Kremsdorf et al., 1984). 
subtypes. Additionally and supported by the taxonomic tree constructed with the most common EV-associated types, our isolate belongs to HPV 17 type but it is clearly segregated from the prototype. The divergence was further characterized by a bootstrap value of $100 \%$, similar to HPV 5 and 15 subtypes (Fig. 3). Then, despite the limitation of this study regarding the complete sequencing of the L1 gene, our results point to the description of a probable novel subtype of HPV 17.

HPV 17b was categorized as a subtype after PCR and sequence analysis from renal transplant recipients (AF097699) (Berkhout et al., 2000). Our results revealed 95.1\% (254/267 bp) identity with subtype b, which was partially sequenced. This finding reinforces the idea that we identified a possible new subtype. The phylogenetic tree showed that the isolate analyzed is closer to the prototype than the genome of subtype $b$, potentially making it a deep evolutionary variation from type 17. The commensal nature of cutaneous types (Antonsson et al., 2000) favors infection at several sites and the mucosal tropism of the identified isolate was probably not random. The oral cavity has a large HPV spectrum and may be implicated in the evolution of this virus, allowing it to adapt to sites other than its original niche, may drive to produce adaptive variants of this genotype.

Acknowledgments. This work was supported by the Conselho Nacional de Desenvolvimento Científico e Tecnológico (CNPq No. 303560/2012-6), Pro-Reitoria de Pesquisa e Pós-Graduação da Universidade Federal Fluminense (PROPPi-UFF), and Fundação de Amparo à Pesquisa do Estado do Rio de Janeiro (FAPERJ, No. E-26/ 111.255/2014). We thank the Plataforma de Sequenciamento de DNA of the Universidade Federal Fluminense and André Victor Barbosa for his technical assistance.

\section{References}

Altschul SF, Madden TL, Schäffer AA, Zhang J, Zhang Z, Miller W, Lipman DJ (1997): Gaped BLAST and PSI-BLAST: a new generation of protein database search programs. $\mathrm{Nu}$ cleic Acids Res. 25, 3389-3402. https://doi.org/10.1093/ $\underline{\text { nar/25.17.3389 }}$

Antonsson A, Forslund O, Ekberg H, Sterner G, Hansson BG (2000): The ubiquity and impressive genomic diversity of human skin papillomaviruses suggest a commensalic nature of these viruses. J. Virol. 74, 11636-11641. https:// doi.org/10.1128/JVI.74.24.11636-11641.2000

Benson DA, Karsch-Mizrachi I, Lipman DJ, Ostell J, Sayers EW (2008): GenBank. Nucleic Acids Res. 304, D25-30.

Berkhout RJ, Bouwes Bavinck JN, Schegget J (2000): Persistence of human papillomavirus DNA in benign and (pre)malignant skin lesions from renal transplant recipients. J. Clin. Microbiol. 38, 2087-2096.

Bottalico D1, Chen Z, Dunne A, Ostoloza J, McKinney S, Sun C, Schlecht NF, Fatahzadeh M, Herrero R, Schiffman M,
Burk RD (2011): The oral cavity contains abundant known and novel human Papillomaviruses from the Betapapillomavirus and Gammapapillomavirus genera. J. Infect. Dis. 204, 787-792. https://doi.org/10.1093/infdis/jir383

Delius H (1986): Characterization of a new type of human papillomavirus (HPV) related to HPV5 from a case of actinic keratosis. J. Virology 154, 389-394.

Delius H, Hofmann B (1994): Primer-directed sequencing of human papillomavirus types Curr. Top. Microbiol. Immunol. 186, 13-31. https://doi.org/10.1007/978-3-642-78487-3 2

Delius H, Saegling B, Bergmann K, Shamanin V, de Villiers EM (1998): The genomes of three of four novel HPV types, defined by differences of their L1 genes, show high conservation of the E7 gene and the URR. Virology 240, 359-365. https://doi.org/10.1006/viro.1997.8943

De Villiers EM, Fauquet C, Broker TR, Bernard HU, zur Hausen H (2004): Classification of papillomaviruses. Virology 324, 17-27. https://doi.org/10.1016/j.virol.2004.03.033

De Villiers EM (2013): Cross-roads in the classification of papillomaviruses. Virology 445, 2-10. https://doi.org/10.1016/j. virol.2013.04.023

Edgar RC (2004): MUSCLE: multiple sequence alignment with high accuracy and high throughput. Nucleic Acid Res. 32, 1792-1797. https://doi.org/10.1093/nar/gkh340

Ensser A, Pfister H (1990): Epidermodysplasia verruciformis associated human papillomaviruses present a subgenus-specific organization of the regulatory genome region. Nucleic Acids Res. 18, 3919-3922. https://doi.org/10.1093/ nar/18.13.3919

Ekström J, Bzhalava D, Svenback D, Forslund O, Dillner J (2011): High throughput sequencing reveals diversity of Human Papillomaviruses in cutaneous lesions. Int. J. Cancer 129, 2643-2650. https://doi.org/10.1002/ijc.26204

Fuchs PG, Iftner T, Weninger J, Pfister H (1986): Epidermodysplasia verruciformis-associated human papillomavirus 8:genomic sequence and comparative analysis. J. Virol. $58,626-634$.

Hazard K, Andersson K, Dillner J, Forslund O (2007): Human Papillomavirus subtypes are not common. Virology 362, 6-9. https://doi.org/10.1016/j.virol.2007.03.004

Kel AE, Gößling E, Reuter I, Cheremushkin E, Kel-Margoulis OV, Wingender E (2003): MATCH: a tool for searching transcription factor 306 binding sites in DNA sequences. Nucleic Acids Res. 31, 3576-3579. https://doi.org/10.1093/ nar/gkg585

Kiyono T, Adachi A, Ishibashi M (1990): Genome organization and taxonomic position of human papillomavirus type 47 inferred from its DNA sequence Virology 177, 401-405. https://doi.org/10.1016/0042-6822(90)90500-Q

Kremsdorf D, Favre M, Jablonska S, Obalek S, Rueda LA, Lutzner MA, Blanchet-Bardon C, Van Voorst Vader PC, Orth G (1984): Molecular cloning and characterization of the genomes of nine newly recognized human papillomavirus types associated with epidermodysplasia verruciformis. J. Virol. 52, 1013-1018.

Li Yh, Chen G, Dong XP, Chen HD (2004): Detection of epidermodysplasia verruciformis-associated human papillomavirus DNA in nongenital seborrhoeic keratosis. Br. J. Dermatol. 
151, 1060-1065. https://doi.org/10.1111/j.1365-2133 $.2004 .06244 . \mathrm{x}$

Matys V, Kel-Margoulis OV, Fricke E, Liebich I, Land S, Barre-Dirrie A, Reuter I, Chekmenev D, Krull M, Hornischer K, Voss N, Stegmaier P, Lewicki-Potapov B, Saxel H, Kel AE, Wingender E (2006): TRANSFAC ${ }^{\circledast}$ and its module TRANSCompel ${ }^{\circledR}$ : transcriptional gene regulation in eukaryotes. Nucleic Acids Res. 34, D108-110. https://doi.org/10.1093/nar/gkj143

May M, Helbl V, Pfister H, Fuchs PG (1991): Unique topography of DNA-protein interactions in the non-coding region of epidermodysplasia verruciformis-associated human papillomaviruses. J. Gen. Virol. 72, 2987-2997. https:// doi.org/10.1099/0022-1317-72-12-2989

Nindl I, Gottschling M, Stockfleth E (2007): Human papillomaviruses and non-melanoma skin cancer: basic virology and clinical manifestations. Dis. Markers 23, 247-259. https:// doi.org/10.1155/2007/942650

Pfister H, Fuchs PG, Majewski S, Jablonska S, Pniewska I, Malejczyk M (2003): High prevalence of epidermodysplasia verruciformis-associated human papillomavirus DNA in actinic keratoses of the immunocompetent population. Arch. Dermatol. Res. 295, 273-279. https://doi. org/10.1007/s00403-003-0435-2

Scheurlen W, Gissmann L, Gross G, zur Hausen H (1986): Molecular cloning of two new HPV types (HPV 37 and HPV 38) from a keratoacanthoma and a malignant melanoma.
Int. J. Cancer 37, 505-510. https://doi.org/10.1002/ ijc. 2910370406

Tamura K, Stecher G, Peterson D, Filipski A, Kumar S (2013): MEGA6: molecular evolutionary genetics analysis, version 6.0. Mol. Biol. Evol. 30, 2725-2729. https://doi. org $/ 10.1093 / \mathrm{molbev} / \mathrm{mst} 197$

Thompson JD, Higgins, DG, Gibson TJ (1994): CLUSTAL W: improving the sensitivity of 301 progressive multiple sequence alignment through sequence weighting, position-specific 302 gap penalties and weight matrix choice. Nucleic Acids Res. 22, 4673-4680. https://doi. org/10.1093/nar/22.22.4673

Vasiljevic N, Hazard K, Eliasson L, Ly H, Hunziker A, de Villiers EM, Norrild B, Dillner J, Forslund O (2007): Characterization of two novel cutaneous human papillomaviruses, HPV93 and HPV96. J. Gen. Virol. 88, 1479-1483. https:// doi.org/10.1099/vir.0.82679-0

Yabe Y, Sakai A, Hitsumoto T, Kato H, Ogura H (1991): A subtype of human papillomavirus 5 (HPV-5b) and its subgenomic segment amplified in a carcinoma: nucleotide sequences and genomic organizations. Virology 183, 793-798. https://doi.org/10.1016/0042-6822(91)91013-7

Zachow KR, Ostrow RS, Faras AJ (1987): Nucleotide sequence and genome organization of human papillomavirus type 5 . Virology 158, 251-254. https://doi.org/10.1016/00426822(87)90263-7 